\title{
In pursuit of the optimal hemocompatible left ventricular assist device
}

\author{
Shuab Omer, MD
}

\footnotetext{
From the Division of Cardiothoracic Surgery, The Baylor College of Medicine/Michael E. Debakey VA Medical Center, Houston, Tex.

Disclosures: Author has nothing to disclose with regard to commercial support.

Received for publication Aug 7, 2018; accepted for publication Aug 10, 2018; available ahead of print Sept 25, 2018.

Address for reprints: Shuab Omer, MD, Division of Cardiothoracic Surgery, Baylor College of Medicine/Michael E DeBakey VA Medical Center, 2002 Holcombe Boulevard, Houston, TX 77030 (E-mail: shuab.omer@bcm. edu).

J Thorac Cardiovasc Surg 2019;157:600-1

$0022-5223 / \$ 0.00$

Published by Elsevier Inc. on behalf of The American Association for Thoracic Surgery https://doi.org/10.1016/j.jtcvs.2018.08.024
}

Left ventricular assist device (LVAD) implantation is a firmly established treatment modality for advanced heart failure; however, major complications such as nonsurgical bleeding, driveline infections, pump thrombosis, and stroke limit wider application to patients with less severe heart failure. Of note, more than $60 \%$ of patients who receive a continuous flow LVAD experience such severe adverse events within the first year. ${ }^{1}$

The HeartMate 3 LVAD (Abbott Inc, Chicago, Ill) was developed with novel design features, including centrifugal flow, a magnetically levitated rotor with no mechanical bearings, wide blood flow passages, and an artificial pulse mode. The pulse mode was designed to reduce thrombotic events and mimic physiologic flow. The 2year results of the Momentum 3 trial $^{2}$ demonstrated superiority of the HeartMate 3 over the HeartMate II axialflow pump on survival free of disabling stroke, reoperation from device malfunction, and thrombosis, but it is disappointing that no difference in the incidence of gastrointestinal bleeding, stroke, and driveline infections was noted.

In comparison, the EVAHEART (Evaheart Inc, Houston, Tex) LVAD was designed with a hydrodynamically levitated bearing, large blood flow gaps, lower operational revolutions per minute range, and a pulsed flow feature created by a significant flow difference between systole and diastole. A better hemocompatible profile of the EVAHEART has been attributed to decreased shear resulting from enhanced clearance between the impeller and the pump housing, better pulsatility, and the mechanical seal system with a recirculating purge system (Cool-Seal), which may contribute to a low hemolysis rate. In this cool-seal system, the seal temperature is maintained at less than $40^{\circ} \mathrm{C}$ to prevent heat denaturation of blood proteins. $^{3}$

In this issue of the Journal, Zayat and colleagues, ${ }^{4}$ using a circulatory mock-loop, present an in vitro comparison of armamentarium.

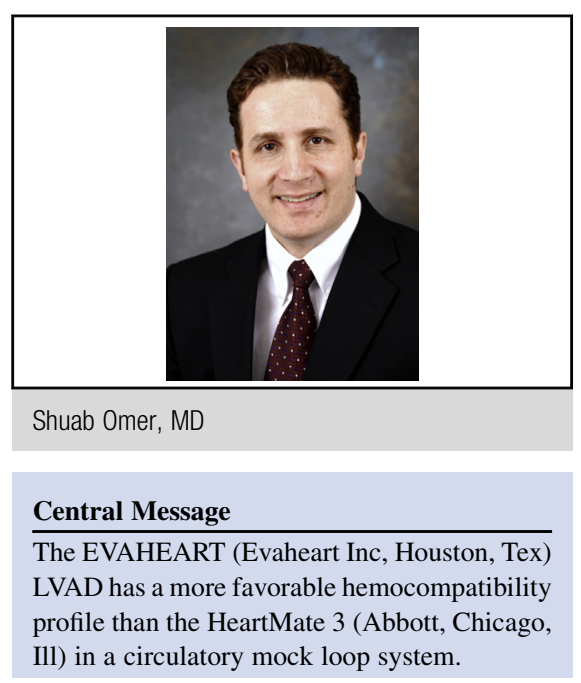

See Article page 591

hemocompatibility between the EVAHEART and the HeartMate 3 centrifugal LVADs. They demonstrate less hemolysis, lower coagulation activation, and better preservation of the von Willebrand factor functional activity with the EVAHEART compared with the HeartMate 3. Clinical studies to date in Japan have demonstrated that the EVAHEART LVAD has lived up to its promise of having very low nonsurgical bleeding rates, possibly related to the better hemocompatible profile. In the first 96 patients who received the EVAHEART, no gastrointestinal bleeding was noted and the Japanese Registry for Mechanically Assisted Circulatory Support reports a 3-year postoperative bleeding rate of only $6.2 \% .^{5,6}$ In contrast, the rate of bleeding events in patients with the HeartMate 3 reached $15 \%{ }^{7}$

However, caution should be exercised in generalizing these results because in vitro studies are unable to recreate native cardiovascular anatomy containing metabolically active endothelial cells and organs. The plastic tubing used to create the mock loops can activate multiple hematologic pathways, and the nonpulsatile rigid tubes by themselves instead of the pump alone can cause Von Willebrand factor degradation and shear injury to blood components. $^{8-10}$ Thus, for wider acceptance of the EVAHEART LVAD, well-designed clinical trials might have to be undertaken to clarify its role in LVAD 


\section{References}

1. Kirklin JK, Pagani FD, Kormos RL, Stevenson LW, Blume ED, Myers SL, et al. Eighth annual INTERMACS report: special focus on framing the impact of adverse events. J Heart Lung Transplant. 2017;36:1080-6.

2. Mehra MR, Goldstein DJ, Uriel N, Cleveland JC Jr, Yuzefpolskaya M, Salerno C, et al. Two-year outcomes with a magnetically levitated cardiac pump in heart failure. N Engl J Med. 2018;378:1386-95.

3. Yamazaki K, Litwak P, Tagusari O, Mori T, Kono K, Kameneva M, et al. An implantable centrifugal blood 370 pump with a recirculating purge system (Cool-Seal system). Artif Organs. 1998;22:466-74.

4. Zayat R, Moza A, Grottke O, Grzanna T, Fechter T, Motomura T, et al. In vitro comparison of the hemocompatibility of two centrifugal left ventricular assist devices. J Thorac Cardiovasc Surg. 2019;157:591-9.e4.

5. Saito S, Yamazaki K, Nishinaka T, Ichihara Y, Ono M, Kyo S, et al. Post-approval study of a highly pulsed, low-shear-rate, continuous-flow, left ventricular assist device, EVAHEART: a Japanese multicenter study using J-MACS. J Heart Lung Transplant. 2014;33:599-608.
6. Nakatani T, Sase K, Oshiyama H, Akiyama M, Horie M, Nawata K, et al. Japanese registry for Mechanically Assisted Circulatory Support: first report. J Heart Lung Transplant. 2017;36:1087-96.

7. Mehra MR, Naka Y, Uriel N, Goldstein DJ, Cleveland JC Jr, Colombo PC, et al. A fully magnetically levitated circulatory pump for advanced heart failure. $N$ Engl $\mathrm{J}$ Med. 2017;376:440-50.

8. Restle DJ, Zhang DM, Hung G, Howard JL, Kallel F, Acker MA, et al Preclinical models for translational investigations of left ventricular assis device associated von Willebrand factor degradation. Artif Organs. 2015 39:569-75.

9. Dassanayaka S, Slaughter MS, Bartoli CR. Mechanistic pathway(s) of acquired von Willebrand syndrome with a continuous-flow ventricular assist device: in vitro findings. ASAIO J. 2013:59:123-9.

10. Wever-Pinzon O, Selzman CH, Drakos SG, Saidi A, Stoddard GJ, Gilbert EM et al. Pulsatility and the risk of nonsurgical bleeding in patients supported with the continuous-flow left ventricular assist device HeartMate II. Circ Heart Fail. 2013;6:517-26. 